\title{
Comfort Zone: Model or metaphor?
}

\author{
Mike Brown
}

The University of Waikato

\begin{abstract}
The comfort zone model is widespread within adventure education literature. It is based on the belief that when placed in a stressful situation people will respond by overcoming their fear and therefore grow as individuals. This model is often presented to participants prior to activities with a highly perceived sense of risk and challenge which arouses strong emotional and physical responses to novel tasks (e.g., ropes courses or rock climbing activities). Students are encouraged to think about 'stretching themselves' by moving outside their comfort zone, to expand their preconceived limits and by inference learn (and become better people). This paper explores theories from cognitive and social psychology, based on the work of Piaget and Festinger respectively, that underpin the comfort zone model. The perpetuation of this model which uses risk to promote situations of disequilibrium/dissonance does not find strong support in educational literature. It is therefore suggested that the comfort zone model be reframed as a metaphor, for possible discussion post activity, rather than being used as a model to underpin programming and pedagogy in adventure education settings.
\end{abstract}

\section{Introduction}

The comfort zone model or variants of it, is widespread within adventure education literature (e.g., Exeter, 2001; Luckner \& Nadler, 1997; Prouty, Panicucci, \& Collinson, 2007). It is based on the belief that when placed in a stressful or challenging situation people will respond, rise to the occasion and overcome their hesitancy or fear and grow as individuals. I have purposefully used the term adventure education in this paper to refer to the particular branch of outdoor education that has developed with a primary focus on developing interpersonal and intrapersonal relationships (Priest \& Gass, 1997). The role of perceived risk is an integral component of the adventure education model (Leberman \& Martin, 2003; Zink \& Leberman, 2001). The pedagogical approach employed in adventure education is well summed up in the following quote,

To maximize safety, adventure professionals structure risk in a manner that causes participants to perceive it as being enormously high, while in actuality it is much lower than perceived and more acceptable as a medium for producing functional change and growth. By responding to seemingly insurmountable tasks, participants often learn to overcome self-imposed perceptions of their capabilities to succeed. (Priest \& Gass, 1997, p. 17)

Within this model personal growth or transformation is dependent on the participant being placed in a stressful situation (Estrellas, 1996). This approach assumes that the 'adventure professional' is competent and capable of assessing each individual's level of perceived risk to ensure that optimal learning will occur.

The comfort zone is often presented graphically as shown in Figure 1. The basic premise of the comfort zone model is well stated by Luckner and Nadler (1997) who claim that,

Through involvement in experiences that are beyond one's comfort zone, individuals are forced to move into an area

Panic zone

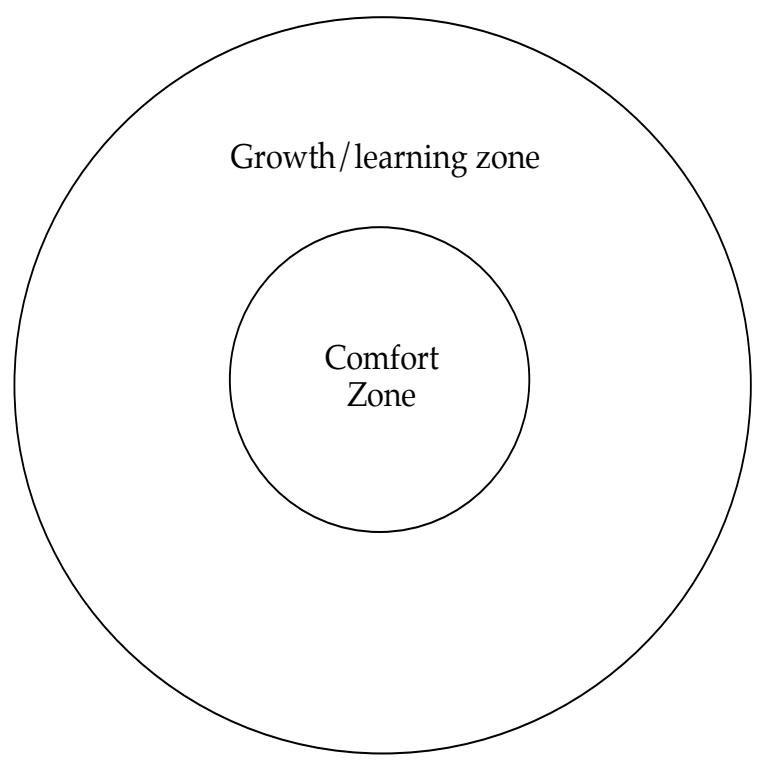

Figure 1. Comfort zone model. Adapted from Pannicucci (2007) 
that feels uncomfortable and unfamiliar - the groan zone. By overcoming these anxious feelings and thoughts of selfdoubt while simultaneously sampling success, individuals move from the groan zone to the growth zone. (p. 20)

When being presented with the comfort zone model students are often asked, "What does it feel like when you are inside your comfort zone?", "What does it feel like when you are outside your comfort zone?" and "What might prevent you from moving outside your comfort zone?" Student answers often include physiological responses (increased heart rate, sweating etc) as well as psychological reactions (feeling of panic, fear, excitement etc). Frontloading, emphasising the key learning points prior to the experience (Priest \& Gass, 1997), might include discussions about the desirability of learning as a life-long process, the factors that may have prevented the student from expanding his/her comfort zone in the past, and identifying reasons that were used for not trying new things. I have observed students writing excuses that they have used for not trying new things on a notepad and then ceremonially burning the piece of paper, writing positive statements on their arm before an activity which they subsequently read to provide inspiration if they doubted themselves, or providing their buddy with a key word or phrase to call out to encourage them.

Panicucci (2007) articulates some of the popular notions around the comfort zone model in the following quotations.

Some would argue that it is the proper use of stretch-zone experiences that is the catalyst in using adventure education to promote learning. (p. 38)

Experience has shown that learning occurs when people are in their stretch zone. Intellectual development and personal growth do not occur if there is no disequilibrium in a person's current thinking or feeling. (p. 39)

How does the stretch zone work? It exposes students. Their usual defenses are taken away, and there is an opportunity to experience their inner being - to have wonderful ideas. People rarely take themselves to this place purposefully because it is uncomfortable, so it is a special growth opportunity when they are brought there during a carefully facilitated experience. (p. 41)

There are many potentially problematic issues and unsubstantiated assumptions presented here. For example the proposition that 'exposing' students is positive, that somehow by stripping away defences one reveals an "inner being," that an "inner being" is somehow a stable and true reflection of one's self. How acceptable is it for an instructor with no clinical training to encourage a student with a history of depression to take risks given that the outcome of participation is uncertain? Does the associated anxiety and potential for failure reinforce existing beliefs and compound a pre-existing or otherwise latent condition? These questions become increasingly salient when one considers Davis-Berman and Berman's (2002) finding that outdoor leaders often receive little or no instruction in assessing emotional risk and "any discussion of anxiety - a central component to emotional risk - is non-existent" (p. 308). Zink and Leberman (2001) drawing on Estrellas (1996), point out, "the manipulation of risk can be dysfunctional when the risk is to [sic] great, as this can cause high levels of stress, which in turn may impact negatively on individuals and groups" (p. 52). Davis-Berman and Berman (2002) have also suggested that, "by intentionally heightening the perception of risk in outdoor programs, staff may be pushing participants beyond their ability to cope effectively and may be creating unacceptably high levels of anxiety in participants" (p. 30).

It is also interesting to observe students' talk following the introduction of this model. It often appears that reference to being 'outside of one's comfort zone' becomes the measure of success in other aspects of the programme. As Long (2001) has pointed out, participants in adventure activities can be socialised into commonly shared understandings of what an activity is 'about.' Individual meaning making is partially determined by the discourse(s) that frame an activity. What is spoken of may underpin ensuing discussions but equally what is 'unspoken' during framing an activity may exclude future interpretations of experiences. If discussion prior to an activity focuses on the concept of 'stretching one's comfort zone' it is highly probable that being 'in' or 'out' of one's comfort zone, becomes by default a measure of the 'effectiveness' of an activity for learning. By inference, if you are in your comfort zone you are not learning, if you are out of your comfort zone you are learning. Such binary assumptions are worth unpacking and examining if we are serious about understanding the conditions for optimal learning. In this paper I examine aspects of Piagetian cognitive development and Festinger's theory of cognitive dissonance which underpin the comfort zone model. In doing so, I problematise some of the underlying assumptions from an educational perspective and suggest that in light of other, more positive approaches to encouraging change, that this model be repositioned as a metaphor to aid student understanding of learning rather than as the underlying principle of programme design. 


\section{What is a comfort zone?}

The term 'comfort zone' is not only readily referred to in the literature but it is also prevalent in the discourse of adventure education practitioners. But what is a comfort zone? How do you know if it is growing? Is there one 'universal' comfort zone that defines or limits my behaviour across all activities or are comfort zones task/context specific? Do my actions indicate that my comfort zone has increased or am I merely performing to complete the task so I can 'get out of here'? Can my comfort zone shrink?

So what does the research on the comfort zone model have to contribute? In two words: very little. This influential component of adventure education theory, in regards to teaching and learning, appears to be built on a rather small base. There does not appear to be a 'comfort zone theory' per se. Searches in main educational and psychological journal databases make no reference to the 'comfort zone' as a theory or model. The term appears as a metaphor in the title in a number of publications (for example, see Eccelstone, 2004) but it does not appear as an educational theory, as for example, experiential learning does. The restricted base on which some components of adventure education practice have been built has also been commented on by Wolfe and Samdahl (2005). In a study which examined ropes course programming, as an example of adventure education, they suggested that the pedagogy utilised is based on two central assumptions: that risk and challenge lead to positive outcomes; and that these benefits are transferable to experiences other than the challenge course. They argued that these assumptions have been accepted as foundational tenets for programming without having been tested as to their veracity.

It appears that the comfort zone model, popularised in adventure education literature, primarily finds its roots in the psychological fields of cognitive development (Piaget, 1977, 1980) and cognitive dissonance (Festinger, 1957). In regard to the terms disequilibrium, cognitive conflict and cognitive dissonance there is, as Fraser (1998) notes, little consistent use of the terms in much of the literature and at times they are used interchangeably. I have tried, where possible, to use the terms as consistently as possible when referring to the original writings relating to these concepts.

While it is clear that Piaget's $(1977,1980)$ concept of the role of cognitive conflict or disequilibrium has been considered important in mainstream instructional strategies involving conceptual change, the epistemology of constructivist learning theory, and child cognitive development, it has also influenced 'traditional' approaches to adventure education theory and practice. It appears that adventure education theorists and practitioners may not have adequately grasped the nuances and the theoretical and hypothetical components of developmental psychology and the limitations of cognitive dissonance. This has resulted in the uncritical and unquestioned acceptance of theories and associated principles which are possibly utilised in an inappropriate or 'blanket' manner. The intention of this paper is not to dismiss Piaget's or Festinger's theories, rather it is to raise some concerns which have a bearing on their applicability in an adventure education context.

\section{A brief introduction to Piaget's theory of cognitive development}

Piaget was interested in describing processes of cognitive development, and the nature of intelligence, "in this sense he was as much an epistemological philosopher as a psychologist" (Kolb, 1984, p. 12). His background was in science and the concepts which form the basis of his theory of cognitive development in children drew heavily on the language and terminology of biology. Piaget is possibly best know for identifying appropriate developmental stages in a child's cognitive development, an approach often referred to as genetic epistemology. His core concern was describing the cognitive development of children from birth to late adolescence.

Piaget compared the process by which children construct understanding of their world to that used by natural organisms adapting to changes in their environment. He maintained that the growth of intelligence is regulated by the same processes that determine the growth of morphology and changes in the physiology of all living systems. (McInerney \& McInerney, 1998, p. 21)

According to Piaget $(1977,1980)$ as children grow they move from a position of having relatively few cognitive structures to interpret the external world of experiences to a more sophisticated stage where they develop the ability to internally organise their own cognitive structures. Just as organisms adapt to the environment to maintain biological balance through the processes of accommodation and assimilation so too do children as they develop their cognitive structures. Piaget was interested in describing the circumstances under which the child develops from one structure to the next.

\section{Assimilation, accommodation and equilibration}

When a new experience is encountered that is similar to previous experiences the child may engage in the process of assimilation. Assimilation involves 
the integration of new experiences into existing cognitive structure which are adequate to incorporate the requirements of the new task (e.g., new experience of drinking juice from a teat rather than milk) (McInerney \& McInerney, 1998). If the new experience is sufficiently different (e.g., drinking from a cup rather than a teat) then the child will engage in the process of accommodation. Accommodation involves the modification of the existing structure to incorporate the new experience (McInerney \& McInerney, 1998). The presentation of a novel task in an adventure education setting may create a tension between what is currently known, or practiced, and the new and unique demands of the task. This tension between the demands of accommodation and assimilation is the driving force to develop new understandings and a new equilibrium (McInerney \& McInerney, 1998). In an ideal educational setting every experience a learner has would involve both the requirements for assimilation and accommodation. However, if an experience

is so far from an organism's cognitive structure that it cannot be accommodated, no learning will take place. For optimal learning to take place, information must be presented that can be assimilated into present cognitive structures, but at the same time, be different enough to necessitate a change in those structures. If the information cannot be assimilated, it simply cannot be understood. (Hergenhahn, 1982, p. 290)

The structures (or in Piaget's terminology 'schema') currently available to a child enables particular thought processes or certain actions to be performed. In other words, how much of the environment a child can understand or even respond to depends on the structures available to it at its present stage of development (e.g., if a child has only grasping or sucking available to them then this is what they will do). According to Piagetian theory a child moves from responding to physical stimulus in the environment (concrete operations) to complex and more abstract problem solving tasks (formal operations) based on cognitive structures that have been established on earlier experiences.

Piaget proposed four cognitive stages in a child's development; sensori-motor (0-2 years), preoperational (2-7 years), concrete operational (7-12 years), and formal operational (12 years + ). For Piaget the driving force that impels the child to either assimilate new facts into existing structures or to modify existing knowledge to include new facts (accommodation) is the desire to maintain equilibration. "Piaget assumed that all organisms have an innate tendency to create a harmonious relationship between themselves and their environment.... Equilibration is this innate tendency to organize one's experiences so as to assure maximal adaptation" (Hergenhahn, 1982, p. 285).

\section{Applicability of Piaget's theory and some critiques}

Piaget's theory has both critics and defenders (Egan, 2002; Lourenco \& Machado, 1996). Some of the critiques have focussed on the categorisation of what is deemed to be developmental appropriate within certain stages, whilst others (see Egan, 2002) have mounted a strong argument critiquing the very foundations of Piaget's approach. For example, the assertion that one always seeks equilibrium when faced with new knowledge which requires either assimilation or accommodation appears to be an assumption or hypothesis which is difficult to substantiate. The proposition of equilibrium as a necessary condition is of a conceptual nature rather than a 'fact' that can be substantiated by empirical studies. Without getting into an extended debate about the merits of a postformal stage or stages it is apparent that the notion of equilibrium is a contested and controversial issue. It has been suggested that there is a post-formal stage of development, a stage proposed beyond Piaget's formal thinking stage (variously occurring between 11-15 years of age). Advocates of a post-formal stage argue that this additional stage, or in some proponents theories, stages, allows us to account for cognitive development after adolescence. For example, Riegel (1975) suggests that the 'dialectical stage,' is characterized by the fact that the individual is "able to accept contradictions as the basis of all thought and to tolerate conflicting operations without equilibriating them under all circumstances (p.61)" (cited in Lourenco \& Machado, 1996, p. 155).

Kramer (1983) argues that a "post-formal stage allows us to handle the relativistic nature of knowledge, the acceptance of contradiction, and the integration of contradiction into an overriding whole" (cited in Lourenco \& Machado, 1996, p. 155). Regardless of which stage we attribute post adolescent development to it is apparent that people are able to accept the relativistic nature of knowledge and the acceptance of contradiction (Lourenco \& Machado, 1996).

Another criticism of Piaget's theory says, in its mild version, that the theory provides vague explanations of cognitive development, and in its strong version, that the theory describes much but explains little ... equilibration, considered by Piaget the most fundamental principle of cognitive development, is a metaphor at best (Ferreira da Silva, 1982), a superfluous concept at worst (Bruner, 1959; Zazzo, 1962). (Lourenco \& Machado, 1996, p. 152) 
The concepts of accommodation, assimilation and equilibrium are but one way to account for an individual's process of learning. As Halford (1989) points out even within cognitive psychology there are competing theories of cognitive development and Zohar and Aharon-Kravetsky (2005) argue that whilst the promotion of cognitive conflict is a significant instructional method there is still inconclusive evidence regarding the effectiveness of this strategy.

Keeping abreast of current debates and critiques of underlying theories is of importance to adventure educators if we are to ensure that the practices which we utilise have solid foundations.

\section{Application of Piaget's theory to adventure education}

Care should be taken not to interpret Piaget's theory as if it were a stimulus-response relationship; creating disequilibrium through stress = learning. A stimulus-response approach assumes that a person is a passive recipient who develops response capabilities by accumulating habits. In contrast, Piaget's theory posits that the cognitive structures that a child has developed from experiences provide the potential to deal with the environment in certain ways, that is, they provide the interpretive framework to understand further experiences (Hergenhahn, 1982). Previous experiences and the cognitive structures available permit the child to construct meaning, as needed from new experiences. What is assimilated or accommodated depends on the child's needs/ desires. If the experiences that are provided are too novel and too far from a person's normal activities and experiences it is possible that rather than being accommodated they will be dismissed as irrelevant or impossible. As Hergenhahn (1982) cautions, "If something is so far from an organism's cognitive structure that it cannot be accommodated, no learning will take place" (p. 290).

Difficulties arise when one confuses providing a stimulus and observing a response which is then equated with learning. For example, as Brookes (2003a) has pointed out, providing students with a challenge on the ropes course will elicit a range of relatively predictable behaviours in students (fear, anxiety, perseverance, a 'buzz' etc.). He refers to this as 'conformist effects.' He also cautions against confusing conformity effects, which are temporary, with educational change. I argue that some adventure education practices (e.g., using the perception of risk to create 'conflict' between one's thoughts of possible physical harm and the reality of the situation) actually encourage and elicit conformity in behaviours which, if not recognised and critiqued, are normalised by adventure educators who use certain activities to evoke a predictable response. This, I suggest, is not how Piaget's theory of cognitive development should be implemented. Piaget was not particularly interested in the pedagogical implications of his observations. Using stressful situations in adventure education illustrates the power of direct experiences in eliciting context specific behaviours. However, as Brookes (2003a, 2003b; 2003c) suggests, behaviour in an adventure education context may be a poor predictor of behaviour in non-adventure education specific contexts. The placing of a student in a challenging position which elicits a particular behaviour does not necessarily mean that they are learning.

\section{Insights from cognitive dissonance}

Coming from social psychology, the theory of cognitive dissonance (Festinger, 1957) is concerned with how a person deals with inconsistency between their cognitions. Cognitions refer to elements of knowledge that people have about their beliefs, actions and their environment. In adventure education, attempts to create a state of dissonance between participants' beliefs and actions are evidenced through the use of novel tasks or activities, often with a perception of difficulty or risk. Cognitions can be: (i) unrelated or irrelevant, having no bearing on each other; (ii) consonant, related and in agreement or; (iii) dissonant, related and contradictory. Cognitive dissonance theory is premised on the belief that people will interpret an event or experience to maintain consistency between their beliefs, actions and behaviours. The motivation to,

reduce dissonance is directly proportional to the magnitude and importance of the discrepant cognitions, and inversely proportional to the magnitude and importance of the consistent cognitions. This tension is typically reduced by changing one of the cognitions, or adding new cognitions until mental 'consonance' is achieved. (Cooper \& Carlsmith, 2001, p. 2112)

While it is accepted that attitudes can effect behaviour, cognitive dissonance theory explains how the reverse is also true - under certain conditions your behaviour can lead to a change in your attitude. When faced with a situation where there is a conflict between their beliefs and their actions people may reduce their dissonance "by changing one of their cognitions, or by adding new cognitions until mental 'consonance is achieved" (Cooper \& Carlsmith, 2001, p. 2112). Examples of strategies that an individual might employ include: a) retrospectively justifying that the effort was worth the result; for example, spending years gaining a PhD is an achievement which I value, if this were not the case I would have cognitive dissonance-why did I bother?; b) appealing to the effect of forced or induced compliance. If, for example, a smoker is asked to give a speech on the merits of non-smoking, is it likely 
that he/she will change his/her view of smoking? According to cognitive dissonance theory it would depend on why he/she agreed to give the speech in the first place. If they had been offered a large sum of money it is highly likely that there would be no change in attitude. The payment was sufficiently large to justify giving the speech, "I did it for the money." If on the other hand they did it for nothing, or for a small sum of money, then it is more likely that his/her attitude to smoking may have changed. The reason, posited by cognitive dissonance theory, is that there is no adequate external justification for giving the speech and therefore to reduce the dissonance the smoker provides a 'logical' explanation - the views expressed in the speech were those that he/she believed.

The two explanations offered above, justification of effort and forced compliance, are ways of explaining the logical inconsistencies that a person might come across. "The question is whether all cases of dissonance reduction boil down to an analogous tendency to keep cognitions logically consistent. A number of authors believe that some non-cognitive, emotional factors often also play a role" (Gleitman, 1986, p. 375). The suggestion that resolution of dissonance might not be attributable to purely logical inconsistencies gave rise to the introduction of self-perception theories by way of explanation. According to Aronson's (1968) hypothesis, dissonance is a significant motivational factor in the maintenance of positive self-concept, that is, maintaining a favourable picture of ourselves. In this view dissonance occurred when a person's belief that he/she was a good person was placed in doubt by behaviour that undermined this belief. In the previous two examples we can see how this hypothesis might function. I have a $\mathrm{PhD}$ which satisfies my desire to have a favourable self-picture. Likewise, our smoker who has received no financial gain to justify his/her anti-smoking speech, may change his/her attitude to maintain his/her self-image as a moral person who seeks to do the right thing. If he/she wants to persuade others of the benefits of non-smoking, he/she is required to modify his/her own views to appease his/ her conscience.

Aronson predicted that dissonance arousal would be more frequent and more powerful among those with high selfesteem - that is, among those whose past history had led them to believe that their high internal standards of behaviour were likely to be achieved. By contrast, Aronson predicted that those with low self esteem, who were accustomed to behaving less competently, would not be surprised or discomforted to find themselves once again behaving in an incompetent manner. (Cooper \& Carlsmith, 2001, p. 2113)
It appears that people with high self-esteem are likely to be both more susceptible to arousal induced by dissonance, but also more resistant to its effects as they can focus on their strengths which mitigates the need to reduce the dissonance (Cooper \& Carlsmith, 2001).

In a further revision of the theory, Cooper and Fazio (1984) postulated that dissonance occurs when a person believes that "their behaviour has been responsible for bringing about consequences that are unwanted or aversive. If there are no such consequences, then inconsistent behaviour will not produce the state of dissonance" (Cooper \& Carlsmith, 2001, p. 2114). Cooper and Fazio (1984) argue that if a person believes that they have responsibility of an aversive event then this is the more likely cause of the ensuing cognitive dissonance than a cognitive inconsistency. More recently, Cooper (1999) has suggested that dissonance is "caused by a discrepancy between the outcome of a behavioural act and the standard to which it is compared" (cited in Cooper \& Carlsmith, 2001, p. 2114). Sometimes this standard will be personal and at other times it might be judged against broader cultural norms.

The immediately aforementioned revisions of Festinger's original theory feature an emphasis on self-concept and cultural norms as the driving force for resolving inconsistencies in cognitions about behaviour, attitudes and the environment rather than appealing to the need to maintain logical consistency between conflicting conceptual propositions. Whilst Festinger's original theory of cognitive dissonance has undergone a number of revisions what the theory does do, in its different forms, is provide a framework for thinking about the possible motivations for change when people are faced with inconsistencies between thoughts and actions. What is clear is that there appear to be various 'triggers' for creating dissonant conditions and these triggers are, like people, different and certainly not uniform and predictable.

\section{Cognitive dissonance/disequilibrium and learning}

Cognitive dissonance or disequilibrium has been applied in the classroom context through a variety of strategies to effect conceptual change. Strategies to foster conceptual change are based on creating an element of disequilibrium or discord within the learner between their initial conception and the principle to be taught; i.e., an existing understanding of events/ rationale can potentially be changed by presentation of a more appropriate scientific explanation. However, disequilibrium between discrepant events may lead to a change in conceptual understandings, or it may not! There has been considerable research which supports both the negative and positive effects of the use of cognitive conflict as a teaching strategy. For example, 
Zohar and Aharon-Kravetsky (2005) argue that for low achieving students the use of cognitive conflict as a teaching strategy can actually hinder their progress in class.

It appears that not only do students of various abilities respond differently to the use of dissonance but also that the degree of dissonance has differing effects, some discrepant events can be powerful in stimulating conceptual change while others have no effect at all. Major disequilibrium can have two effects: a restructuring of conceptual understanding; or the rejection of anomalous data (Rea-Ramirez \& Clement, 1998). It was found that rather than giving up their previous conceptions to accommodate the new information students in science classes were likely to either reject the new information or classify it as only appropriate to 'school' settings which is not valid in the 'real world' (Rea-Ramirez \& Clement, 1998). Driver, Guesne and Tiberghien (1985) have commented that the restructuring of concepts takes time and favourable circumstances, not just the observation of a discrepant event.

It may be that disequilibrium is to some extent unavoidable, and beneficial for some students on some occasions. However, the premise that the active promotion of disequilibrium is necessary to promote learning is contestable. A situation which engenders disequilibrium may be treated by learners as too great a 'leap' in understanding and meaning in which case they might reject it outright or otherwise consign it to the 'not valid in the real world' file. Students may ignore the experience, attribute it to luck, the efforts/ support of others, or accept only sufficient aspects of the experience to make peripheral changes in their prior conceptions. For example, does the student view 'success' on the rock face as being related to success in other aspects of life? It may well be that the cognition created, "I can achieve" is seen as unrelated to 'achievement' in other settings, and therefore, no dissonance has arisen for the individual. If the individual does not place much weight on the value of the cognitions, they believe them to be trivial and of little importance, then little dissonance is likely to occur. The occurrence of one dissonant cognition, "I can achieve success on the ropes course" does not mean that this single event will replace other multiple cognitions regarding the individual's ability in other settings requiring physical skill or application of perseverance. The level of dissonance is also inversely proportional to the number of cognitions that support a particular belief of ability; years of socialisation and behavioural expectations are unlikely to be replaced by a single event, particularly when it is experienced in a novel or highly contrived environment.

Whilst Rea-Ramirez and Clement's (1998) work focussed on studying conceptual change through the use of dissonance in science education it is useful in that it casts light on students' ability to compartmentalise new knowledge as being valid only in particular contexts (at school and therefore not 'real') in order to prevent a conflict of ideas from arising. There is no reason to suspect that 'in the outdoors' and 'real life' are not seen as separate contexts where different ideas/standards apply. Students' ability to 'compartmentalise' is supported by Wattchow and Johnson's (2004) findings in relation to students' perspectives of environmental issues following a long stay outdoor education experience. The research revealed how students considered the bush and the city as totally unrelated and therefore they had no desire or interest in becoming involved in environmental projects upon returning to their homes in an urban setting. They had in effect differentiated knowledge into 'outdoor' and 'real world' compartments which were seen as disconnected, thus avoiding dissonant cognitions.

The contradictory and inconclusive findings certainly do not give a clear and unambiguous mandate for creating situations which engender dissonance or disequilibrium as an effective learning strategy for all students. Simply placing a person in a potentially stressful situation does not guarantee a state of cognitive dissonance. Even if discrepant events occur people will invariably have a number of different ways of rejecting or reconciling these apparently dissonant cognitions. Even if we assume that being 'outside of one's comfort zone' equates to experiencing cognitive dissonance we are still not able to equate this state with learning. As Fraser (1998) states, "it cannot be claimed that conflict through disequilibrium is always a catalyst for cognitive development" (p. 46).

\section{Where to from here?}

Arguably, Piaget's greatest contribution is not the often cited structuralist approach identified in the four developmental stages, but rather his promotion of constructivism, the principle that learners construct their own understandings through interaction with the world. Constructivism, itself the subject of critique (Egan, 2002), is not premised on the need to place students in a position 'outside their comfort zone' in order to learn. One of the tenets of constructivist approaches to learning is that students start with the concrete world with which they are familiar. As detailed above, simply placing people in stressful situations which places them outside their 'comfort zone' does not necessarily lead to learning.

To re-iterate the central issues:

i) Piaget was interested in describing the process of cognitive development not enunciating a pedagogy for adventure education; 
ii) The processes of assimilation, accommodation and equilibrium are hypothetical constructs that not amenable to empirical testing (nor for that matter capable of being disproved);

iii) It is possible that people are able to hold 'contrary views' in the post-formal stage of cognitive development, therefore the desire to maintain equilibrium is not a necessity;

iv) How one might learn does not necessarily mean that you should construct lessons on that basis. For example, we know that touching a hot plate is painful and results in a burn. From a behaviourist perspective we have a strong observable stimulusresponse pattern evident: touch-pain; therefore don't touch. Does that mean that the most effective way to teach children that an element is hot is to place their hand on it?;

v) Students have the ability to compartmentalise concepts as belonging to 'other than the real world.' hence avoiding dissonant situations;

vi) Some discrepant events lead to change, some do not. Research indicates both the positive and negative effects of using cognitive conflict as a teaching strategy;

vii) Ascertaining individuals response to stress, anxiety, conditions of cognitive dissonance is a difficult task.

Perhaps it is timely to re-emphasize the social factors in development and avoid a 'black box' approach where learning is conceived of something that goes on inside one's head in a social vacuum. As Bandura (1986) states,

Cognitive learning is fostered through tuition, modelling, and performance feedback, rather than confined to the influence of mismatching experiences of unguided action. Most of the cognitive skills and structures used in daily pursuits are cultivated socially, rather than transform themselves asocially. ( $p$. 483)

\section{Conclusion}

Adventure educators have taken the concepts of dissonance/disequilibrium and applied them in a rather functionalist or stimulus-response manner. Accommodation-assimilation-equilibrium are conceptual descriptions of a child's cognitive development processes (note they are descriptive not explanatory). To take this concept and apply it as a teaching strategy is a simplistic reading of a descriptive concept. As Boud and Walker (1993) remind us "learning from experience is far more indirect than we often pretend it to be" (p. 85). Using a description of how we learn, modifying it to promote 'stressful situations,' and applying it as an instructional strategy has given rise to a teaching and learning approach which, I suggest, has placed adventure education on an educational limb; a limb that finds us struggling to gain credibility within the mainstream educational discourse. In relative isolation we tend to draw on some foundational texts that have not been critically examined, are repeatedly referenced, and through which the field continues to perpetuate taken-for-granted assumptions as defining principles of adventure education theory and practice. The centrality of the concepts of challenge and risk to the field are examples of how a discourse has been built up around an approach to adventure education that finds its basis in the notion that personal growth and learning primarily occur when an individual is placed in a situation outside their 'comfort zone.' However, as Leberman and Martin (2003) have pointed out, activities in which students had been pushed outside of their 'comfort zones' were not necessarily the activities that resulted in peak learning experiences. I suggest that the adoption of the comfort zone model and the assumptions that underpin it have less than desirable consequences in terms of student engagement, psychological well-being and emotional safety. As educators we hear the success stories and vocal affirmations but what of the silences and unspoken thoughts that are subsumed in the rush for appropriate closure of an activity?

I am not advocating that we abandon challenging and adventurous activities with our students: far from it. Opportunities for 'authentic risk taking' where fabricated stress is minimised, where there is dialogue about risk and genuine personal choice fosters "an environment which encourages appropriate risk taking" (Estrellas, 1996, p. 34) and the potential for positive learning outcomes. What I am cautioning against is the use of the comfort zone as a model for learning that is used an as explanation for how we learn and therefore the justification for intentionally engineering or 'cooking up' situations to place students outside their 'comfort zone.'

Stress is a consistent element of wilderness adventures, just as it is a consistent part of life. However, stress should not be manipulated further in the guise of facilitating transformative experiences. Stress is known to cause physiological and psychological damage. To purposefully create stressful situations as a companion to risk taking blatantly fosters an environment of negative outcomes. (Estrellas, 1996, p. 42) 
Creating a perception of risk and challenging people to move outside their 'comfort zone' is seen as an integral feature for growth and change in participants of 'traditional approaches' to adventure education programmes. Using stress as the way to achieve growth may possibly have taken on the mantle of an 'urban myth' in education in the outdoors. Recent research (Berman \& Davis-Berman, 2005; Davis-Berman \& Berman, 2002; Estrellas, 1996; Leberman \& Martin, 2003; Zink \& Leberman, 2003), and the central tenet of this paper is that it is perhaps time to advocate for a paradigm shift in the way leaders frame and conduct adventure education programmes. Davis-Berman and Berman (2002) have argued that the greatest amount of change comes when participants feel safe, secure and accepted. They have argued that,

more productive avenues to growth and change exist, based on participants' safety and security. The paradigm shift suggested ... reflects a movement toward a more intrinsic model of motivation to change. This model is based on emotional safety and stability in programs, rather than an emphasis on increasing risk and moving out of comfort zones. (Davis-Berman \& Berman, 2002, p. 310)

Effective learning depends on solid foundations and strong relationships of trust and support between educator and learner and between learners (Vella, 2002). For example, the concepts of reciprocal learning and autonomy/self-determination (Bishop \& Glynn, 1999) create new metaphors for teaching and learning and reframe the relationship between educators and learners. Learning can be viewed as a gradual and cumulative process rather than a sudden quantum shift in understanding. Learning can and will occur in activities that do not create a strong perception of risk (Leberman \& Martin, 2003). Let us provide students with favourable conditions for authentic and meaningful experiences where they are challenged in an appropriate manner and suitably supported by those with a genuine interest in their learning informed by sound educational principles. It is time to reposition the comfort zone model as metaphor; a metaphor to describe how we might think about learning and growth rather than a rationale for implementing dubious teaching and learning practices.

\section{Acknowledgements}

My thanks to Deborah Fraser for comments on an earlier draft and to the reviewers who provided feedback which enhanced the paper.

\section{References}

Aronson, E. (1968). Dissonance theory: Progress and problems. In R. Ableson, E. Aronson, W. McGuire, T. Newcomb, M. Rosenberg \& P. Tannenbaum (Eds.), Theories of cognitive consistency: A sourcebook (pp. 5-27). Chicago: Rand McNally.

Bandura, A. (1986). Social foundations of thought and action: A social cognitive theory. Englewood Cliffs, NJ: Prentice-Hall.

Berman, D., \& Davis-Berman, J. (2005). Positive psychology and outdoor education. Journal of Experiential Education, 28(1), 17-24.

Bishop, R., \& Glynn, T. (1999). Culture counts: Changing power relations in education. Palmerston North, New Zealand: Dunmore Press.

Boud, D., \& Walker, D. (1993). Barriers to reflection on experience. In D. Boud, R. Cohen \& D. Walker (Eds.), Using experience for learning (pp. 73-86). Buckingham, UK: Society for Research into Higher Education \& Open University Press.

Brookes, A. (2003a). Character building. Why it doesn't happen, why it can't be made to happen, and why the myth of character building is hurting the field of outdoor education. In 13th National Outdoor Education Conference Proceedings (pp. 19-24). Adelaide, South Australia: Outdoor Educators Association of South Australia.

Brookes, A. (2003b). A critique of Neo-Hahnian outdoor education theory. Part one: Challenges to the concept of "character building." Journal of Adventure Education and Outdoor Learning, 3(1), 49-62.

Brookes, A. (2003c). A critique of Neo-Hahnian outdoor education theory. Part two: "The fundamental attribution error" in contemporary outdoor education discourse. Journal of Adventure Education and Outdoor Learning, 3(2), 119-132.

Cooper, J. (1999). Unwanted consequences and the self: In search of the motivation for dissonance reduction. In E. Harmon-Jones \& J. Mills (Eds.), Cognitive dissonance: Progress on a pivotal theory in social psychology (pp. 149173). Washington: APA.

Cooper, J., \& Carlsmith, K. (2001). Cognitive Dissonance. In N. Smelser \& P. Baltes (Eds.), International encyclopedia of the social and behavioural sciences (pp. 2112-2114). Amsterdam: Elsevier.

Cooper, J., \& Fazio, R. (1984). A new look at dissonance theory. Advances in Experimental Social Psychology, 17, 229-266.

Davis-Berman, J., \& Berman, D. (2002). Risk and anxiety in adventure programming. Journal of Experiential Education, 25(2), 305-310.

Driver, R., Guesne, E., \& Tiberghien, A. (1985). Children's ideas in science. Philadephia, PA: Open University Press. 
Eccelstone, K. (2004). Learning in a comfort zone: Cultural and social capital inside an outcome based assessment regime. Assessment in Education: Principles, Policy and Practice, 11(1), 29-47.

Egan, K. (2002). Getting it wrong from the beginning: Our progressivist inheritance from Herbert Spencer, John Dewey, and Jean Piaget. London: Yale University Press.

Estrellas, A. (1996). The eustress paradigm: A strategy for decreasing stress in wilderness adventure programming. In K. Warren (Ed.), Women's voices in experiential education (pp. 32-44). Dubuque, IA: Kendall Hunt.

Exeter, D. (2001). Learning in the outdoors. London: The Outward Bound Trust.

Festinger, L. (1957). A theory of cognitive dissonance. Stanford, CA: Stanford University Press.

Fraser, D. (1998). Partners in problem solving: Children collaborating in pairs. Unpublished Doctoral Thesis, University of Waikato, Hamilton, NZ.

Gleitman, H. (1986). Psychology (2nd ed.). New York: W.W.Norton.

Halford, G. (1989). Reflections on 25 years of Piagetian cognitive developmental psychology, 1963-1988. Human Development, 32, 325-357.

Hergenhahn, B. (1982). An introduction to theories of learning. Englewood Cliffs, NJ: Prentice-Hall.

Kolb, D. A. (1984). Experiential learning. Englewood Cliffs, NJ: Prentice-Hall.

Leberman, S., \& Martin, A. (2003). Does pushing comfort zones produce peak learning experiences? Australian Journal of Outdoor Education, 7(1), 10-19.

Long, A. (2001). Learning the ropes: Exploring the meaning and value of experiential education for girls at risk. Journal of Experiential Education, 24(2), 100-108.

Lourenco, O., \& Machado, A. (1996). In defense of Piaget's theory: A reply to 10 common criticisms. Psychological Review, 103(1), 143-164.

Luckner, J. L., \& Nadler, R. S. (1997). Processing the experience: Strategies to enhance and generalize learning (2nd ed.). Dubuque, IA: Kendall Hunt.

McInerney, D., \& McInerney, V. (1998). Educational Psychology: Constructing learning (2nd ed.). Sydney, Australia: Prentice-Hall.

Panicucci, J. (2007). Cornerstones of adventure education. In D. Prouty, J. Panicucci \& R. Collinson (Eds.), Adventure education: Theory and applications (pp. 33-48). Champaign, IL: Human Kinetics.
Piaget, J. (1977). The development of thought (A. Rosin, Trans.). New York: Viking Press.

Piaget, J. (1980). Adaptation and intelligence (G. Eames, Trans.). Chicago: University of Chicago Press.

Priest, S., \& Gass, M. A. (1997). Effective leadership in adventure programming. Champaign, IL: Human Kinetics.

Prouty, D., Panicucci, J., \& Collinson, R. (Eds.). (2007). Adventure education: Theory and applications. Champaign, IL: Human Kinetics.

Rea-Ramirez, M., \& Clement, J. (1998, 19-22 April). In search of dissonance:The evolution of dissonance in conceptual change theory. Paper presented at the Annual meeting of the National Association for Research in Science Teaching, San Diego.

Vella, J. (2002). Learning to listen, learning to teach. San Francisco, CA: Jossey-Bass.

Wattchow, B., \& Johnson, D. (2004). Their words/Their voices: Student perspectives' of the Camp Mallana outdoor education experience. Paper presented at the Connections and Disconnections: International Outdoor Education Conference, Bendigo, Australia.

Wolfe, B., \& Samdahl, D. (2005). Challenging assumptions: Examining fundamental beliefs that shape challenge course programming and research. Journal of Experiential Education, 28(1), 25-43.

Zink, R., \& Leberman, S. (2001). Risking a debate - refining risk and risk management: A New Zealand case study. Journal of Experiential Education, 24(1), 50-57.

Zink, R., \& Leberman, S. (2003). Risking a debate-redefining risk and risk management: A New Zealand study. New Zealand Journal of Outdoor Education: Ko Tane Mahuta Pupuke, 1(2), 63-76.

Zohar, A., \& Aharon-Kravetsky, S. (2005). Exploring the effects of cognitive conflict and direct teaching for students of different academic levels. Journal of Research in Science Teaching, 42(7), 829-855.

\section{About the author}

Mike Brown PhD is a senior lecturer in the Department of Sport and Leisure Studies at The University of Waikato. He has worked in outdoor education in the UK, Australia and New Zealand. He has recently returned to an academic position following two and a half years instructing in the field. In addition to academic pursuits he is a keen sea kayaker and telemark skier. Email: michaelb@waikato. ac.nz 